\title{
Sexual Harassment \\ in Higher Education \\ - Experiences and Perceptions among Students at a Danish University
}

\author{
BY Bontu lucie Guschie, Kaitlin Busse, Farhiya Khalid, \\ SARa Louise MuHr and Sine Nørholm Just
}

\begin{abstract}
Taking higher education to be an arena in which professional and social interaction has a special propensity to overlap, this paper investigates university students' experiences and perceptions of sexual harassment. Based on survey data, we find varying responses according to their gender and nationality, indicating that men and Danish students are least likely to experience and perceive situations as sexual harassment. Further, we find a wide-spread normalization of certain potentially offensive acts and behaviours. In addition, students report varying degrees of acceptability of certain acts, depending on context. On this basis, we argue that normalization hinders individual students' ability to recognize and denounce sexual harassment. The influence of social norms on individual experiences and perceptions, we assert, means sexual harassment is neither an objective category nor an individual responsibility. In consequence, issues of sexual harassment can only be dealt with if and when universities assume responsibility for the norms that prevail within their spheres of influence.
\end{abstract}

\section{KEYWORDS}

\section{Higher education, sexual harassment, university students, Denmark, normalization}

Bontu Lucie Guschke, PhD Fellow, Department of Organization, Copenhagen Business School (CBS).

Kaitlin A. Busse, Fulbright Student Researcher, Department of Organization, CBS.

Farhiya Khalid, master's student, Department of Communication and Arts, Roskilde University.

Sara Louise Muhr, Professor, Department of Organization, CBS.

Sine Nørholm Just, Professor, Department of Communication and Arts, Roskilde University. 


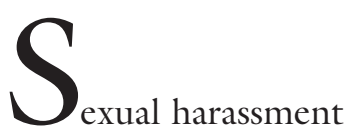

abounds in professional and social contexts alike and is also known to be prevalent in student environments (Bennson and Thomson 1982; Kenig and Ryan 1986; Fitzgerald et al. 1988; Mazer and Percival 1989). In Denmark, experiences of sexual harassment among university students were brought to the public's attention when, in February 2018, 48 students from the five Danish universities sent an open letter to the presidents of their universities, which was published in the newspaper, Information (Dragsdahl 2018). The letter was critical of how the universities dealt with cases of sexual harassment and asked for more active engagement in terms of policies for prevention as well as retributory action.

Since sexual harassment is most frequently experienced by women between the ages of 18 and 29 years (FRA 2015), the occurrence of sexual harassment at universities should not come as a surprise. Nevertheless, sexual harassment in the workplace is a far more recognized and researched topic than sexual harassment at universities. Universities are, of course, professional organizations; however, students are not employees, meaning their relation to the organization is different from that of staff. Further, university students are adults, meaning their interactions with faculty and other staff - and among themselves - are not regulated in the detailed manner that is common in primary and secondary schools. In these respects, students occupy a grey area. Moreover, the majority of the studies of students' experiences of sexual harassment that do exist measure the frequency of these in the United States (US) context of college campuses. This paper will add to existing knowledge in two ways. First, it will focus on the neglected demographic group of university students (outside the US), adding to what little is already known about their perceptions and experiences. Secondly, it will not only explore how frequently sexual harassment occurs, but also focus on the contexts in which it occurs and how the involved individuals make sense of such situations.

Using both quantitative and qualitative data from a survey that was answered by 342 students at a Danish university, we aim to show the difficulties in interpreting and evaluating experiences of sexual harassment. Sexual harassment is subject to a variety of different legal and administrative definitions (Cortina et al. 1998; Gruber 1992; Fitzgerald et al. 1988; 1995; Fitzgerald and Shullman 1993; Mazzeo et al. 2001; Till 1980) as well as to a range of social interpretations and stigmas (CalderDawe 2015; Fernando and Prasad 2018; Latcheva 2017; Olson et al. 2008; Vachhani and Pullen 2019; Welsh et al. 2006). This makes it very difficult for individuals to know privately and speak out publicly when they have been targets of sexual harassment or exposed others to sexual harassment. Through our analysis, we highlight the ambiguity of the formal definitions of sexual harassment and show the further complexity that sociocultural contexts and personal perceptions add to the matter. Thereby, we focus on conceptualizing the social construction of sexual harassment.

\section{DEFINING SEXUAL HARASSMENT}

In all likelihood, the phenomenon of sexual harassment abounds throughout history, yet the term sexual harassment was only introduced in the 1980s, anticipating the development of a legal language for such actions and experiences. In the literature, Till (1980) is generally recognized as providing one of the earliest conceptualizations. Based on the self-described experiences of a sample of US women college students, he created five behavioural categories: gender 
harassment, seductive behaviour, sexual bribery, sexual coercion, and sexual imposition or assault. Aiming to build a stronger conceptual framework for sexual harassment, Fitzgerald et al. (1988) developed the Sexual Experiences Questionnaire (SEQ), a self-report inventory framework composed of three related but conceptually distinct dimensions: sexual coercion, unwanted sexual attention, and gender harassment (see also Fitzgerald and Shullman 1993). Although others have attempted different classifications - for example, Gruber (1992) identifies 11 specific types of harassment - SEQ continues to be the most widely used framework. Whereas the distinction between sexual coercion and unwanted sexual attention is arguably one of degree, the separation of sexual and gender harassment is particularly useful. As Leskinen et al. (2011) point out, genderbased harassment might be devoid of sexual interest, meaning motives of harassment are embedded in historical and structural gender hierarchies.

In Denmark, sexual harassment was primarily put on the agenda through European Union (EU) initiatives and legislation that links sexual harassment to gender discrimination (Borchorst and Agustin 2017). ${ }^{1}$ Operating within a framework that is similar to Fitzgerald and colleagues', the EU's legal definition of sexual harassment is:

any form of unwanted verbal, non-verbal or physical conduct of a sexual nature (...) with the purpose or effect of violating the dignity of a person, in particular when creating an intimidating, hostile, degrading, humiliating or offensive environment (EU Directive 2006/ 54/EC).

Such behaviour is explicitly prohibited in the EU Equal Treatment Directive (Directive 2006/54/EC) and in the Charter of Fundamental Rights of the EU (\$21 'Nondiscrimination'). Legal action - and de- cades of activism - notwithstanding, sexual harassment and related forms of sexism continue to shape European societies. A recent study, conducted in all 28 EU member-states, and involving 42,000 women respondents, found that $55 \%$ of women have experienced sexual harassment (FRA 2015 ).

Cases of sexual harassment, however, are believed to be underreported. When, in the same study, the informants were asked about the most serious incident of sexual harassment they experienced, $35 \%$ of women answered that they kept the incident to themselves (FRA 2015).

One underlying reason for not reporting may be ambiguity as to what constitutes sexual harassment and what does not. Many people may simply be at a loss as to how to define and make sense of a given experience (Wilson 2000; Rotundo et al. 2001; Latcheva 2017). Additionally, they doubt that they would get help and support if they were to report the incident (Riger 1991; Welsh et al. 2006).

Such individual apprehension is frequently mirrored in the social environment through normalization and/or ridicule of sexual harassment. In talking about experiences of sexism and sexual harassment, many people have found that it only leads to being socially labelled as overly sensitive, overreacting, uptight killjoys (Ahmed 2017). Those who seek to overcome such social stigma are often further stigmatized as 'bitter, self-serving feminists', accused of pursuing trivialities and causing unwarranted trouble (Ahmed 2017; Calder-Dawe and Gavey 2016; Mills 2008; Olson et al. 2008; Whitley and Page 2015).

For the purpose of this paper, sexual harassment is defined as (1) measurable physical, verbal, non-verbal and digital behaviours and acts as well as (2) instances of gendered and sexed hierarchies which are rooted in norms that people draw on when they measure and explain perceived sexual harassment (Phillips 2000; Tolman et al. 
2003). This more subjective and relational definition of sexual harassment opens up space for analyses that look into the normalization of sexual harassment. As Hlavka (2014) says, we cannot rely entirely on measures of sexual harassment. Rather, we must understand sexual harassment as a social phenomenon and look into "how and why these violent acts are produced, maintained, and normalized in the first place" (Hlavka 2014, 338). Given that "so much of what we experience as sexism is dismissed as just what we experience" (Ahmed 2015,5 ), appeals to objectivism are problematic.

This is our starting point. On the one hand, sexual harassment is measurable through a typology of behaviours and observation of their frequency. On the other hand, sexual harassment must be interpreted - by both those experiencing and researching it. Thus, we need more knowledge of how and why it happens. In addition, we must examine how sexual harassment is maintained and normalized.

\section{SEXUAL HARASSMENT AT UNIVERSITIES}

Sexual harassment seems to be especially persistent in study environments (Cortina et al 1998; Fitzgerald et al. 1988; Larssen et al. 2003; ESTHE 2016; Phipps and Young 2015; Whitley and Page 2015). One of the first studies of sexual harassment in a student context examined experiences of sexual harassment reported by a random sample of undergraduate women students at Berkeley. In this survey, 30 percent of the respondents reported that they had received unwanted sexual attention from at least one male instructor during their four years at college (Benson and Thomson 1982). The study concluded that when harassment occurs in student-teacher relationships, women students often lose their academic self-confidence and become disillusioned with male faculty (Bennson and Thomson 1982). These findings were subsequently corro- borated in a series of sexual harassment studies at universities (Kenig and Ryan 1986; Fitzgerald 1988; Mazer and Percival 1989) as well as in high schools (McMaster et al. 2002).

Further, research shows that students remain uncertain as to how to understand sexual harassment. Thus, a study from 1997 that investigated 827 students' perceptions and experiences of sexual harassment at the University of Transkei, South Africa, found that the respondents needed more clarity on what actually constitutes sexual harassment (Mayekiso and Bhana 1997). Another study surveyed 651 men and women undergraduate students during one academic year at a state university in US, showing that women reported higher rates of unwanted contact than men. Across the full sample of students, however, there was a gender difference in knowledge of campus support services, with women being more likely to have attended a prevention programme and to indicate knowledge of rape crisis services (Banyard et al. 2007). Thus, men students' unawareness of what constitutes sexual harassment may fuel women students' uncertainty as to how to define unwanted attention. Hence, the lack of clarity and awareness surrounding sexual harassment results in insecurities from both men and women, which may explain why these acts persist.

Based on this literature review, we constructed our survey to highlight students' understandings and interpretations of sexual harassment as well as the frequency of their encounters with the phenomenon. Further, we sought insights into the role of context as a mediating variable to interpret the character of an experience, just as we included intersectionalities of gender and nationality - as an indicator of cultural background - as one particularly important determinant of participants' interpretative repertoire. 


\section{Methodologi}

The study contributes to the literature by providing further explanations of the interrelations and discrepancies between students' experiences as well as perceptions of sexual harassment. In order to do so, we conducted a survey among students at a Danish university (referred to in the following simply as 'the University').

\section{PARTICIPANTS}

Participants were recruited from the University under the conditions that they were currently enrolled at the University or had graduated within the last 12 months. A total of 342 participants completed the survey. In terms of gender, $64.5 \%$ self-identified as women, $35 \%$ as men, and $0.5 \%$ identified as 'other'. $63 \%$ of respondents considered their main nationality as 'Danish'. 90\% were born between 1990 and 1999 , hence aged 19-28, with a mean age of 26 years. $98 \%$ of the respondents were current students at the University, while $2 \%$ were recent graduates. Of the participants, 96\% identified as full-time students at the University, with $41 \%$ enrolled as bachelor students and 59\% conducting their master studies. Half of the master's students also pursued their bachelor degree at the University.

\section{Procedure ANd measures}

A mixed methods survey was distributed online to students at the University between June and September 2018. It was distributed through programme managers, student associations, University-related social media channels and the University's intranet. It was also sent to all study programme directors, who were asked to share the survey with their students. All students participated voluntarily and anonymously.

The survey consisted of 19 questions. Four were open field questions where students could respond with as little or as much information as they pleased. The remaining 15 survey items were closed category questions, composed of a mixture of single response or multiple-choice questions. Five of these questions included the option of an open field comment (e.g. 'If you have experienced and/or witnessed any of the before-mentioned situations at the University, how did you react?').

The questions can be categorized in four main groups:

(1) Demographic questions, such as gender, age, nationality, educational level (bachelor/master).

(2) Questions on how to define sexual harassment. These included an open field question as well as statements which were rated by the respondents as to whether or not they should be described as acts of sexual harassment (e.g. 'Are the following situations acts of sexual harassment? - unwelcome touching, hugging, and kissing').

(3) Questions on respondents' opinion on whether or not situations of potential sexual harassment were acceptable and/or normal in their study environment, rated on a five-point Likert scale from 'I strongly agree' to 'I strongly disagree' (e.g. 'To make sexual comments is okay at parties/social events at the University', 'It is okay to comment on another person's body if it's meant as a compliment').

(4) Questions regarding respondents' experiences with sexual harassment in their study environment, either personal experiences or witnessing the experiences of others, as well as their reactions (e.g. 'At the University, have you ever experienced any of the following - Someone made negative remarks about me because of my gender or told jokes that 'put down' men/women/LGBTQI people'). This group included both category questions and open field questions, and it contained a closed question on whether the respondents knew where and how to get help in instances of sexual harassment. 
To ensure ethical conduct, the end of the questionnaire provided information as to where students could get support at the University after witnessing or experiencing sexual harassment.

\section{UNDERSTANDING AND PERCEPTION OF SEXUAL HARASSMENT}

As a first step, the respondents were asked to indicate which acts they perceived to belong to the category of sexual harassment. To ensure comparability to other studies, the options were consistent with the categories of a recent EU FRA (2015) survey on 'Violence against women', which draws on the original SEQ framework. In the EU survey, however, all categories are defined as acts of sexual harassment and are used to investigate the extent of sexual harassment against women in the EU. Rather than assuming a specific definition of sexual harassment, we asked students for their perceptions based on the multiple acts listed in the survey (see table 1 ).
Here, the main finding is that while a majority of the respondents perceive the mentioned physical acts as sexual harassment, understandings vary more regarding the verbal aspects of sexual harassment. To illustrate, $56 \%$ of the respondents think that 'sexually suggestive comments, or jokes that offend you' are acts of sexual harassment and 59\% think that intrusive comments about your physical appearance that offend you' are acts of sexual harassment. $29 \%$ and $28 \%$, respectively, say that those are 'maybe' acts of sexual harassment. 15\% and $13 \%$ disagree. There are even less students who responded that inappropriate invitations to go out on dates' (26\%), 'intrusive questions about your private life that offend you' $(28 \%)$, and 'inappropriate staring or leering that intimidates you' $(40 \%)$ are acts of sexual harassment.

Looking at non-verbal acts without direct physical contact, the majority of the respondents define these situations as acts of sexual harassment (76\% for each). As regards cyber harassment, the students are

Table 1. Participants' responses based on whether they perceive certain situations as acts of sexual harassment as a whole.

\section{Acts of Sexual Harassment}

Unwelcome touching, hugging and kissing

Sexually suggestive comments, or jokes that offend you

Inappropriate invitations to go out on dates

Intrusive questions about your private life that offend you

Intrusive comments about your physical appearance that offend you

Inappropriate starring or leering that intimidates you

Somebody sending or showing you sexually explicit

pictures, photos, or gifts that offend you

Somebody indecently exposing themselves to you

Inappropriate advances that offend you on social networking websites such as Facebook, Snapchat, Instagram, etc
Yes Maybe No

$85 \% \quad 14 \% \quad 1 \%$

$56 \% \quad 29 \% \quad 15 \%$

$26 \% \quad 39 \% \quad 35 \%$

$28 \% \quad 44 \% \quad 28 \%$

$59 \% \quad 28 \% \quad 13 \%$

$40 \% \quad 37 \% \quad 24 \%$

$76 \% \quad 17 \% \quad 7 \%$

$76 \% \quad 16 \% \quad 8 \%$

$51 \% \quad 34 \% \quad 16 \%$ 
split with 51\% answering yes, 34\% maybe and $16 \%$ no.

Overall, the percentage of respondents choosing to answer 'maybe' to the categories in the survey ranged from 14-44\%. Replies to the open field question ('How would you define sexual harassment?') provide one potential explanation of these relatively high numbers: students' understanding of what is and what is not sexual harassment varies from one situation to another. Here is one highly representative example:

[Sexual harassment is] when my boundaries have been crossed and I do not feel comfortable. It's subjective and depends on the circumstances. (Danish woman, born 1994) In addition to the sensitivity to context, there are significant differences in the perception of situations as acts of sexual harassment between people of different gender. With the exception of the category 'somebody indecently exposing themselves to you', women are significantly more likely to perceive that all categories in the survey are, indeed, acts of sexual harassment (see table 2).

Interestingly, there are also significant differences between nationalities (Danish vs. non-Danish) (see table 3 ). With the exception of the categories 'unwelcome touching, hugging and kissing' and 'somebody sending or showing you sexually explicit pictures, photos, or gifts that offend you', respondents who indicate that they are 'Danish' are significantly less likely to

Table 2. Participants' responses based on whether they perceive certain situations as acts of sexual harassment based on gender (answering 'yes').

\section{Acts of Sexual Harassment}

Unwelcome touching, hugging and kissing

Sexually suggestive comments, or jokes that offend you

Inappropriate invitations to go out on dates

Intrusive questions about your private life that offend you

Intrusive comments about your physical appearance that offend you

Inappropriate starring or leering that intimidates you

Somebody sending or showing you sexually explicit pictures, photos, or gifts that offend you

Somebody indecently exposing themselves to you

Inappropriate advances that offend you on social networking websites such as Facebook, Snapchat, Instagram, etc

\section{Women Men}

Chi-Squared Results

$\begin{array}{lll}90 \% & 73 \% & \mathrm{X} 2(2)=20.597, \mathrm{p}=.000 * * \\ 68 \% & 34 \% & \mathrm{X} 2(2)=60.414, \mathrm{p}=.000^{* * *} \\ 33 \% & 13 \% & \mathrm{X} 2(2)=37.559, \mathrm{p}=.000^{* * *} \\ 36 \% & 12 \% & \mathrm{X} 2(2)=27.960, \mathrm{p}=.000^{* * *} \\ 72 \% & 36 \% & \mathrm{X} 2(2)=43.316, \mathrm{p}=.000^{* * *} \\ 50 \% & 20 \% & \mathrm{X} 2(2)=53.390, \mathrm{p}=.000^{* * *} \\ 81 \% & 66 \% & \mathrm{X} 2(2)=10.933, \mathrm{p}=.004 * * \\ 79 \% & 71 \% & \mathrm{X} 2(2)=2.570, \mathrm{p}=.277 \\ 59 \% & 36 \% & \mathrm{X} 2(2)=21.000, \mathrm{p}=.000^{* * *}\end{array}$

${ }^{*} \mathrm{p}<.05,{ }^{* *} \mathrm{p}<.01,{ }^{* * *} \mathrm{p}<.001$ 
Table 3. Participants' responses based on whether they perceive certain situations as acts of sexual harassment based on nationality (answering 'yes').

\section{Acts of Sexual Harassment}

Unwelcome touching, hugging and kissing

Sexually suggestive comments, or jokes that offend you

Inappropriate invitations to go out on dates

Intrusive questions about your private life that offend you

Intrusive comments about your physical appearance that offend you

Inappropriate starring or leering that intimidates you

Somebody sending or showing you sexually explicit pictures, photos, or gifts that offend you

Somebody indecently exposing themselves to you

Inappropriate advances that offend you on social networking websites such as Facebook, Snapchat, Instagram, etc

\section{Danish Non-Danish Chi-Squared Results}

$\begin{array}{lll}84 \% & 85 \% & \mathrm{X} 2(2)=.298, \mathrm{p}=.862 \\ 48 \% & 70 \% & \mathrm{X} 2(2)=23.093, \mathrm{p}=.000 * * * \\ 23 \% & 30 \% & \mathrm{X} 2(2)=12.902, \mathrm{p}=.002 * * \\ 24 \% & 33 \% & \mathrm{X} 2(2)=6.855, \mathrm{p}=.032^{*} \\ 57 \% & 62 \% & \mathrm{X} 2(2)=6.007, \mathrm{p}=0.0496^{*} \\ 34 \% & 49 \% & \mathrm{X} 2(2)=9.824, \mathrm{p}=.007 * *\end{array}$

$72 \%$

$81 \%$

$\mathrm{X} 2(2)=3.163, \mathrm{p}=.206$

$72 \%$

$83 \%$

$\mathrm{X} 2(2)=11.389, \mathrm{p}=.003 * *$

$41 \%$

$67 \%$

$\mathrm{X} 2(2)=21.533, \mathrm{p}=.000 * * *$

${ }^{*} \mathrm{p}<.05,{ }^{* *} \mathrm{p}<.01,{ }^{* * *} \mathrm{p}<.001$

perceive any of the categories as acts of sexual harassment compared to 'non-Danish' respondents. The difference is especially high in the category 'sexually suggestive comments, or jokes that offend you' where $70 \%$ of non-Danes label this as an act of sexual harassment, compared to $48 \%$ of Danes (see table 3 ).

These results suggest discrepancies between participants' perceptions of different acts of sexual harassment. Importantly, multiple respondents noted that the subjective nature and importance of context made it difficult to determine whether an act should be considered sexual harassment. It is, therefore, necessary to explore the nuances of how sexual harassment is understood by different individuals in specific situations and/or social contexts.

\section{ACCEPTANCE OF ACTS OF (POTENTIAL) SEXUAL HARASSMENT}

To gain such nuance, the survey included a set of questions on the respondents' opinions of whether or not various situations of 
Table 4. Participants' responses based on whether they perceive certain situations of sexual harassment as okay (answering 'yes').

\section{Is It Okay?}

To make jokes on people's gender

To make sexual comments at parties/social events

Physical contact between students without outspoken consent at parties/social events

To persuade someone into sex or other sexual activities

To force yourself on a women even if she says no

To force yourself on a man even if he says no

Sending sexually explicit pictures, after you talked with them at a party/social event

Comment on person's body if meant as a compliment

Comment on person's body if meant as a joke

Staring/leering at another person's body at a party/social event

Staring/leering at another person's body in class

\section{I strongly I disagree disagree}

$20 \%$

$22 \%$

$24 \%$

$53 \%$

$89 \%$

$86 \%$

$48 \%$

$4 \%$

$31 \%$

$19 \%$

$25 \%$
$26 \%$

$25 \%$

$21 \%$

$19 \%$

$9 \%$

$10 \%$

$32 \%$

$13 \%$

$36 \%$

$30 \%$

$38 \%$
I neither agree
nor disagree

$27 \%$

$30 \%$

$17 \%$

5\%

$28 \%$

$21 \%$

5\%

$5 \%$

$9 \%$

$4 \%$

$1 \%$

$1 \%$

0\%

$2 \%$

$2 \%$

$1 \%$

$18 \%$

$2 \%$

$2 \%$

$37 \%$

$36 \%$

$10 \%$

$20 \%$

$10 \%$

$3 \%$

$25 \%$

$22 \%$

$4 \%$

$21 \%$

$13 \%$ potential sexual harassment were acceptable and/or normal in their study environment (see table 4).

Again, a main finding is that physical acts are predominantly evaluated as 'not okay'. To illustrate, $98 \%$ of women and $96 \%$ of men disagree that 'it can be okay to force yourself on a woman/man, even if she/he says no', and $72 \%$ disagree that 'it is some- times okay to persuade someone into sex or other sexual activities'.

However, only $45 \%$ of students disagree that 'physical contact between students without outspoken consent is okay at parties/social events at the University'. Here, we find further indications of students' situational sensitivity, suggesting that acts of potential sexual harassment might be more 
accepted or normalized in certain social contexts such as 'parties/social events'. This is supported by other findings; thus, while $26 \%$ of the students agree that if there is a party/social event at the University, staring or leering at another person's body is okay', only 17\% agree that the same situation was okay 'in class'. The open field responses confirm that participants' levels of acceptability towards an act of sexual harassment change according to social context. Specifically, the consumption of alcohol is seen as a determining factor for whether certain acts are seen as 'okay' or 'not okay':

Unwanted physical contact happens often at parties when people are under the influence of alcohol. (Danish man, born 1991)

Usually the line for what is and isn't appropriate is blurred when alcohol is involved. (non-Danish woman, born 1993)

Unfortunately, I think it has become quite natural and for some people 'okay' to touch females on their ass or boobs. So, I think this is a quite normal experience for many females when attending parties, especially when people are drinking alcohol, it is suddenly okay! (Danish woman, born 1993)

Thus, it seems that certain acts of sexual harassment are normalized in the context of parties and social events, even if these are associated with the University.

It is also interesting to look at verbal acts and their acceptance. About a quarter of respondents agree that 'it is okay to make jokes on people's gender' and 'it is okay to make sexual comments at parties/social events at the University' (28\% and $22 \%$, respectively), while about half of the students disagree (46\% and $48 \%$ ). This issue, then, seems to be divisive and, perhaps, debated among the students themselves - as indicated by the high number of participants who used the open field option to elaborate on whether or not, why, and in which situa- tions such jokes are okay. Here, respondents displayed many different opinions. First, many emphasised that sexual jokes form part of social interaction:

People make jokes about everything and that's totally okay! (non-Danish man, born 1995)

I [do] not find them [jokes] to be a problem. Making jokes about men, women and LGBTQ+ should not be discouraged. (...) If we worry too much about being offended, then no one will be able to say or do anything anymore. (Danish man, born 1997)

Please, jokes (comedy) should not be considered sexual harassment, comedy is comedy. Unless it comes to verbal abuse, free speech should not be punished. (non-Danish man, born 1996)

Second, some believe it is the responsibility of the receiver to draw the line:

Jokes about women and men as a group are quite common and I feel like if you have a problem with these kind[s] of jokes it is your own responsibility to address it, when it is relevant. (Danish man, born 1994)

Third, some are more ambivalent about responsibility; again, highlighting the importance of context:

I agree [that] joke[s] about gender [are] not okay if it is with ill intent and are trying to hurt other people with it, otherwise I think it is totally fine and you know the audience can appreciate the joke. (Danish man, born 1994)

You should be able to joke about anything, but the premise of your joke etc. should not be from a place of sexism or racism. (Danish woman, born 1990)

The problem, however, is that it is difficult to tell how the receiver feels, which results 
Table 5. Participants' responses based on whether they perceive certain situations of sexual harassment as okay based on gender (answering 'yes').

\section{Female Male}

\section{Is It Okay?}

To make jokes on people's gender

To make sexual comments at parties/ social events

Physical contact between students without outspoken consent at parties / social events

To persuade someone into sex or other sexual activities

\subsection{4}

To force yourself on a women even if she says no

To force yourself on a man even if he says no

Sending sexually explicit pictures, after you talked with them at a party/ social event

Comment on person's body if meant as a compliment

Comment on person's body if meant as a joke

Staring/leering at another person's body at a party/social event

Staring/leering at another person's body in class

${ }^{*} \mathrm{p}<.05,{ }^{* *} \mathrm{p}<.01,{ }^{* * *} \mathrm{p}<.001$

$\begin{array}{ccccccc}\text { Mean } & \text { SD } & \text { Mean } & \text { SD } & \text { t } & \text { df } & \text { p } \\ 2.39 & 1.08 & 3.29 & 1.28 & -6.86 & 336 & .012 * \\ 2.29 & 1.09 & 3.08 & 1.14 & -6.27 & 338 & .570\end{array}$

$\begin{array}{lllllll}2.42 & 1.18 & 3.00 & 1.19 & -4.32 & 337 & .202\end{array}$

$\begin{array}{lllllll}1.07 & .30 & 1.33 & .74 & -4.58 & 338 & .000 * * *\end{array}$

$\begin{array}{lllllll}1.09 & .33 & 1.48 & .96 & -5.59 & 337 & .000 * * *\end{array}$

$\begin{array}{lllllll}1.67 & .80 & 1.93 & 1.00 & -2.65 & 338 & .327\end{array}$

$\begin{array}{lllllll}3.14 & .96 & 3.71 & .88 & -5.44 & 338 & .795\end{array}$

$\begin{array}{lllllll}1.89 & .91 & 2.75 & 1.13 & -7.53 & 337 & .000 * * *\end{array}$

$\begin{array}{lllllll}2.25 & 1.03 & 3.30 & 1.02 & -9.02 & 338 & .887\end{array}$

$\begin{array}{lllllll}2.00 & .94 & 2.97 & 1.11 & -8.51 & 337 & .010 *\end{array}$

in the following explanations of how the boundary lines between something humorous and offensive gets crossed:

I think it is a grey zone when people make sexist jokes. It might be 'funny' with a single one, but when they are too frequent, they re- ally hurt our authority as women and the general way people speak to and about us. And then it becomes sexual harassment. (Danish woman, born 1994)

Every time the guys spoke, people would listen. When me and the other girl spoke, no 
one would listen, and they would make 'funny' comments about that "it was cute when we were bossy" (...) These comments might sound funny and insignificant, but they really undermine our authority as girls and make it very hard for us to be taken seriously. (...) I have told the guys from my study programme a few times that they were inappropriate, but then they just laugh and make '\#metoo' jokes. I don't think they mean anything evil, they just don't understand how these comments affect their female classmates. (Danish woman, born 1994)

Although some comments suggest that jokes are always okay, most emphasize how

Table 6. Participants' responses based on whether they perceive certain situations of sexual harassment as okay based on nationality (answering 'yes').

\section{Is It Okay?}

To make jokes on people's gender

To make sexual comments at parties/ social events

Physical contact between students without outspoken consent at parties/ social events

To persuade someone into sex or other sexual activities

To force yourself on a women even if she says no

To force yourself on a man even

if he says no

Sending sexually explicit pictures, after you talked with them at a party/ social event

Comment on person's body if meant as a compliment

Comment on person's body if meant as a joke

Staring/leering at another person's body at a party/social event

Staring/leering at another person's body in class

\section{Danish Non-Danish}

$\begin{array}{ccccccc}\text { M } & \text { SD } & \text { M } & \text { SD } & \text { t } & \text { df } & \text { p } \\ 2.90 & 1.23 & 2.37 & 1.17 & 3.90 & 334 & .775 \\ 2.78 & 1.15 & 2.25 & 1.13 & 4.17 & 336 & .957\end{array}$

$\begin{array}{lllllll}2.75 & 1.25 & 2.44 & 1.13 & 2.25 & 335 & .145 \\ 2.06 & 1.24 & 1.71 & 1.07 & 2.60 & 333 & .029 *\end{array}$

$\begin{array}{lllllll}1.18 & .55 & 1.13 & .46 & 0.87 & 336 & .083 \\ 1.26 & .72 & 1.17 & .52 & 1.24 & 335 & .014^{*}\end{array}$

$\begin{array}{lllllll}1.90 & .93 & 1.55 & .77 & 3.54 & 336 & .263 \\ 3.46 & .95 & 3.14 & .97 & 2.97 & 336 & .257\end{array}$

$\begin{array}{lllllll}2.31 & 1.13 & 1.98 & .94 & 2.75 & 335 & .000 * * *\end{array}$

$\begin{array}{lllllll}2.86 & 1.12 & 2.22 & 1.08 & 5.19 & 336 & .499\end{array}$

$\begin{array}{lllllll}2.50 & 1.15 & 2.07 & .98 & 3.49 & 335 & .001 \text { ** }\end{array}$


the specific context, including the audience and the intention of the speaker, makes a difference. Thus, the barrier for what is considered sexual harassment is movable and highly context-dependent.

Answers are more visibly tilted to one side of the scale for the question as to whether 'it is okay to comment on another person's body'. 'If it is meant as a compliment', students tend to agree that it is 'okay', whereas the majority disagree 'if it is meant as a joke'. However, there is a significant difference in the perceptions of women and men respondents regarding the extent to which they feel 'it is okay to comment on another person's body if it is meant as a joke'. The results suggest that women are less likely than men to agree. Moreover, there is a significant difference regarding the extent to which women and men respondents feel 'it is okay to make jokes about people's gender'. Again, women are less likely to find such jokes acceptable. Thirdly, there is a significant difference between women and men respondents' views regarding the extent to which they thought 'staring or leering at another person's body in class is okay', with fewer women finding such behaviour acceptable. In combination, these results suggest that men are generally more likely to condone potential acts of sexual harassment (see table 5 ).

Interestingly, two of the categories also show significant differences related to the respondents' nationality. There was a significant difference between Danes and nonDanes regarding whether they think it is okay to comment on another person's body if it is meant as a joke', indicating that Danes are more likely to find such acts acceptable compared to non-Danes. Furthermore, there was a significant difference between Danes and non-Danes regarding whether they think 'it is okay to stare or leer at another person's body in class'. Again, Danes are more likely to believe that such behaviour is okay (see table 6).
Relatedly, in the open field questions, comments referred to 'Danish culture' or 'Danish humour' to justify certain acts or situations that could be perceived as sexual harassment. Some used this as a justification while others condemned it as a nonjustified excuse:

We Danes have a sense of humor that isn't restricted by too many barriers - which is great if you're not a fan of verbal censorship. (Danish man, born 1996)

Danish people are really open when it comes to our sexuality. Of course we make jokes about different genders, race or preferences. That's what we do. (Danish man, born 1993)

Danish culture has a serious problem with not taking this [sexual harassment] seriously. The amount of downgrading jokes about women, I can't even count. Most of them blame it on Danish humour, to escape racist/sexist accusations. (non-Danish woman, born 1996)

\section{THE OCCURRENCE OF SEXUAL HARASSMENT}

The survey also sought to explore the extent to which certain acts, which are commonly defined as sexual harassment, are experienced and witnessed at the University.

Overall, $40 \%$ of students experienced at least one of the potential acts of sexual harassment at the University (see table 7 for details).

Even more students, namely 58\%, witnessed at least one of the potential acts of sexual harassment at the University (see table 8 for details).

It is commonly acknowledged that women are more likely to experience sexual harassment compared to men (FRA 2015; Whitley and Page 2015). This was mirrored in two categories in our results (see table 9). First, we found a significant gender-based difference regarding those who 
Table 7. Participants' responses based on whether they have experienced certain situations of sexual harassment as a whole.

\section{Experiences of}

Sexual Harassment

Negative remarks about

gender or jokes that

'put down' men/women/

LGBTQI people

Sexual remarks about clothing, body, or sexual activities

Unwanted physical contact with me

Verbally propositioned to participate in sexual activity

Shared material with sexual content online without consent

Exposed themselves indecently

Asked for sexual favours in return for grades, letters of recommendation, ect.

Made explicit, unwanted sexual advances

$12 \% \quad 88 \%$

Pressured me into having sex with them $3 \% \quad 97 \%$

Experienced none of the following

experienced 'someone who made negative remarks about them because of their gender or told jokes that put down men/women/LGBTQI people.' Second, we also found a significant gender-based difference regarding the experience of 'someone who made unwanted physical contact with them'. The survey results also show that two thirds $(67 \%)$ of students think that 'sexual harassment is more of a problem for
Table 8. Participants' responses based on whether they have witnessed certain situations of sexual harassment as a whole.

\section{Witness of}

Sexual Harassment

Yes No

Negative remarks about

women as a group or jokes

that 'put down' women

$44 \% \quad 56 \%$

Negative remarks about men

as a group or jokes that

$22 \% \quad 78 \%$

'put down' men

Negative remarks about

LGBTIQ people as a group

or jokes that 'put down'

$29 \% \quad 71 \%$

LGBTIQ people

Sexual remarks about clothing,

body, or sexual activities

$35 \% \quad 65 \%$

Unwanted physical contact

with me

$20 \% \quad 80 \%$

Verbally propositioned to

participate in sexual activity

$10 \% \quad 90 \%$

Shared material with sexual

content online without consent

$4 \% \quad 96 \%$

Exposed themselves indecently $\quad 3 \% \quad 97 \%$

Asked for sexual favours in

return for grades, letters of

recommendation, ect.

Made explicit, unwanted

sexual advances

$14 \% \quad 86 \%$

Pressured me into having

sex with them

$3 \% \quad 97 \%$

Witnessed none of the following $42 \% \quad 58 \%$

women than for men'. Yet, it should not go unnoticed that overall, $33 \%$ of the men students and $43 \%$ of women students said that they have experienced at least one of the 
Table 9. Participants' responses based on whether they have experienced certain situations of sexual harassment by gender (answering 'yes').

\section{Experience of Sexual Harassment}

Negative remarks about gender or jokes that 'put down' men/women/LGBTQI people

Sexual remarks about clothing, body, or sexual activities

Unwanted physical contact with me

Verbally propositioned to participate in sexual activity

Shared material with sexual content online without consent

Exposed themselves indecently

Asked for sexual favours in return for grades, letters of recommendation, ect.

Made explicit, unwanted sexual advances

Pressured me into having sex with them

Experienced none of the following

${ }^{*} \mathrm{p}<.05,{ }^{* *} \mathrm{p}<.01,{ }^{* * *} \mathrm{p}<.001$
Women Men

Chi-Squared Results

$\begin{array}{rrr}30 \% & 13 \% & \mathrm{X} 2(\mathrm{l})=12.696, \mathrm{p}=.000 * * \\ 26 \% & 19 \% & \mathrm{X} 2(\mathrm{l})=2.039, \mathrm{p}=.153 \\ 24 \% & 12 \% & \mathrm{X} 2(\mathrm{l})=7.760, \mathrm{p}=.005 * * \\ 12 \% & 17 \% & \mathrm{X} 2(\mathrm{l})=1.681, \mathrm{p}=.195 \\ 1 \% & 3 \% & \mathrm{X} 2(\mathrm{l})=1.394, \mathrm{p}=.238 \\ 2 \% & 3 \% & \mathrm{X} 2(\mathrm{l})=.023, \mathrm{p}=.881 \\ 0 \% & 1 \% & \mathrm{X} 2(1)=1.863, \mathrm{p}=.172 \\ 14 \% & 10 \% & \mathrm{X} 2(1)=0.870, \mathrm{p}=.351 \\ 3 \% & 2 \% & \mathrm{X} 2(1)=0.663, \mathrm{p}=.415 \\ 57 \% & 67 \% & \mathrm{X} 2(1)=3.676, \mathrm{p}=.055\end{array}$

situations of (potential) sexual harassment at the University.

Based on the significant differences between respondents' nationality and their perception of situations as acts of sexual harassment as well as their opinion on which situations are acceptable in their study environment, we also checked for potential associations between nationality and participants' experiences of sexual harassment. Similar to earlier results, there were some significant differences. Interestingly, for the same categories in which women are more likely to experience situations of (potential) sexual harassment, people who report their nationality to be Danish are less likely to do so (see table 10).
A similar pattern can be seen in the respondents' evaluation of whether 'sexual harassment is a problem at the University'. Overall, $49 \%$ of the students agreed to this statement. Again, there is a significant difference between women and men, with women being slightly more likely to feel that sexual harassment is a problem at the University compared to men. Likewise, we found a significant difference between Danes and non-Danes, suggesting that Danes are less likely to feel that sexual harassment is a problem at the University compared to non-Danes. 
Table 10. Participants' responses based on whether they have experienced certain situations of sexual harassment by nationality (answering 'yes').

\section{Experience of Sexual Harassment}

Negative remarks about gender or jokes that 'put down' men/women/LGBTQI people

Sexual remarks about clothing, body, or sexual activities

Unwanted physical contact with me

Verbally propositioned to participate in sexual activity

Shared material with sexual content

online without consent

Exposed themselves indecently

Asked for sexual favours in return for grades, letters of recommendation, ect.

Made explicit, unwanted sexual advances

Pressured me into having sex with them

Experienced none of the following

${ }^{*} \mathrm{p}<.05,{ }^{* *} \mathrm{p}<.01,{ }^{* *} \mathrm{p}<.001$
Dane Non-Dane Chi-Squared Results

$\begin{array}{rrr}21 \% & 30 \% & \mathrm{X} 2(\mathrm{l})=4.069, \mathrm{p}=.044^{*} \\ 23 \% & 25 \% & \mathrm{X} 2(\mathrm{l})=.076, \mathrm{p}=.783 \\ 17 \% & 26 \% & \mathrm{X} 2(\mathrm{l})=.4 .374, \mathrm{p}=.036^{*} \\ 14 \% & 13 \% & \mathrm{X} 2(\mathrm{l})=.111, \mathrm{p}=.740 \\ 0 \% & 3 \% & \mathrm{X} 2(1)=4.030, \mathrm{p}=.045^{*} \\ 1 \% & 4 \% & \mathrm{X} 2(1)=2.289, \mathrm{p}=.130 \\ 0 \% & 1 \% & \mathrm{X} 2(1)=1.709, \mathrm{p}=.191 \\ 12 \% & 14 \% & \mathrm{X} 2(1)=.251, \mathrm{p}=.616 \\ 1 \% & 6 \% & \mathrm{X} 2(1)=6.603, \mathrm{p}=.010^{*} \\ 63 \% & 53 \% & \mathrm{X} 2(1)=3.658, \mathrm{p}=.056\end{array}$

\section{Discussion}

The combination of closed and open-field survey questions allowed us to, first, explore relations between perceptions and experiences of sexual harassment; second, to relate these findings to the background variables of gender and nationality; and, third, to identify situational and sociocultural context as intermediating variables for the perception and experience of sexual harassment. We now bring these three elements together in a discussion of, first, the normalization of acts of sexual harassment; second, the question of whose perceptions of a specific act should prevail; and, third, who should take responsibility for chang- ing currently dominant norms at the University.

Our data shows that as long as acts are seen as sexual harassment, they are predominantly deemed unacceptable. Thus, we find a connection between people's perceptions and experiences, confirming the subjective and socially constructed character of sexual harassment. In the context of the University, acts that may be characterized as sexual harassment are particularly normalized in contexts of partying and other social events that involve consumption of alcohol. While most respondents lament this situation, the normalization of verbal forms of sexual harassment, particularly in 
the form of jokes, is more divisive. Some maintain that sexualized jokes are problematic, but many open field responses defend such jokes as an ordinary, even necessary, part of Danish/University culture. These quantitative and qualitative differences between the respondents show that when they try to make sense of sexual harassment, the social environment and broader context cannot be ignored. The personal sensemaking process, as occurring when the individual answers the survey, seems to be influenced by external and sociocultural circumstances. In sum, if people are inclined to believe that certain behaviour does not constitute sexual harassment, they are also more likely to think it is accepted and tolerable - and potentially less motivated to act against it.

Importantly, such interpretation of the actions of others and willingness/ability to counteract sexual harassment is not an individual affair. Rather, each individual's perceptions and experiences are constituted in relation to the norms of the social context in which they occur. This opens up the question of whose definition of sexual harassment and acceptable occurrences (e.g. a joke, a compliment) should prevail - the actor or the recipient? While we do not entirely disregard the role of intention and agree that it may make a difference whether an act of sexual harassment was intended or not, we insist that if an act or comment is experienced as sexual harassment by the recipient, it must be accepted as such by everyone involved. There are several reasons why this should be the case: first, if someone feels comfortable to act or speak in a way that may be interpreted as sexual harassment, that person is likely to be in a position of power and/or privilege in relation to the recipient of the verbal or non-verbal action. Similarly, the actor is likely to feel that the act is within the bounds of what is socially acceptable, based on the specific situation (e.g. a party) and/or the broader context (e.g. the cultural context of Den- mark). Both of these features provide strong disincentives to act or speak up against the initial action, meaning particular attention should be paid to such reactions - even if made well after the incident. While we might wish for consensus to arise if and when different interpretations are in place, a more practicable - and, perhaps, fairer - principle would be recognition that interpretations may vary and respect for the recipient's point of view.

Here, we reach the third issue of whose responsibility it is to install such interpretative principles and, hence, to change the currently prevalent normalization of certain forms of potential sexual harassment - either in general (e.g. sexualized jokes) or in particular situations (e.g. intimate touching at parties). First, and most importantly, this can never be the responsibility of the individual. Just as someone who has experienced sexual harassment is never to blame for that experience, they should not be charged with establishing the basis for calling out the experience. Second, while it seems that the normalization of certain potentially offensive (physical, verbal, nonverbal and digital) acts occurs at the broader level of society, the University context also appears to play a role in normalizing certain behaviours. Not only does it encompass professional as well as personal relations and offer plenty of opportunities for socializing and matchmaking to its students, it is also an international environment in which people with different cultural backgrounds come into close proximity sometimes exposing underlying differences in social norms. For these reasons the University (and universities, as such) has a special responsibility for establishing norms that enable everyone to feel included without any breech of their integrity and dignity. In addition, the University should implement practices for the (preventive and retributory) enforcement of these norms. While our study cannot provide any specific answers as to how the University should go 
about fulfilling this responsibility, it clearly shows that much remains to be done.

\section{CONCLUSION}

Our study demonstrates that sexual harassment is frequently experienced by students at the University. Importantly, however, we did not only ask about the occurrence of sexual harassment, but also studied how it is perceived and defined and whether it is a 'normal' phenomenon. Here, we found that while participants had experienced and witnessed sexual harassment, these occurrences tended to be normalized in certain situations (i.e. social gatherings/parties). Such normalization amplifies the ambiguity of the concept of sexual harassment and makes it difficult to report, object to and prevent sexual harassment (Calder-Dawe 2015; Hlavka 2014). If people are inclined to believe that certain behaviour does not constitute sexual harassment, they may also think it is acceptable and tolerable - and become less motivated to act against it. As the FRA (2015) study showed, sexual harassment is systematically underreported. Our study reveals that the very normalization of offensive behaviour - that is, the social construction of it as an acceptable part of daily life - reinforces the occurrence of sexual harassment and discourages reporting, allowing the phenomenon to persist.

Moreover, our results show that people of Danish nationality are less likely to understand certain acts, especially verbal ones, as sexual harassment. This indicates that the normalization of sexual harassment may be more prominent in Danish culture. In acknowledging the degree to which social norms have been internalized, our findings demonstrate the dangers of reducing sexual harassment to an individual issue. In the context of our study, it must be the responsibility of the University to intervene, just as other professional and social organizations must assume responsibility for the normalization of individual acts within their spheres of influence.

\section{Note}

1. While it is common to think of sexual harassment in terms of a male perpetrator and a female victim, the reverse relationship as well as same-sex harassment are not excluded from the definition. Further, transgender and intersex people (and members of queer communities, more generally) may be particularly susceptible to harassment as well as other forms of sex- and/or gender-based violence and abuse (Fileborn 2012).

\section{REFERENCES}

- Ahmed, S. 2015. Introduction: Sexism: A problem with a name. New Formations. 86, 5-13.

- Ahmed, S. 2017. Living a Feminist Life.

Durham: Duke University Press.

- Banyard, V.L., Ward, S., Cohn, E.S., Plante, E.G., Moorhead, C. and Walsh, W. 2007. Unwanted sexual contact on campus: A comparison of women's and men's experiences. Violence and Victims. 22(1), 52-70. DOI: 10.1891/088667007780482865

- Benson, D.J. and Thomson, G.E. 1982. Sexual harassment on a university campus: The confluence of authority relations, sexual interest and gender stratification. Social Problems. 29(3), 236-51. DOI: $10.2307 / 800157$

- Borchorst, A. and Agustin, L.R. 2017. Seksuel Chikane pa Arbejdspladsen: Faglige, Politiske og Retlige Spor. Aalborg: Aalborg Universitetsforlag. - Calder-Dawe, O. 2015. The choreography of everyday sexism: Reworking sexism in interaction. New Formations. 86, 89-105. DOI:

10.3898/NEWF.86.05.2015

- Calder-Dawe, O. and Gavey, N. 2016. Making sense of everyday sexism: Young people and the gendered contours of sexism. Women's Studies International Forum. 55(March-April), 1-9. DOI: https://doi.org/10.1016/j.wsif.2015.11.004 . Cortina, L.M., Swan, S., Fitzgerald, L.F. and Waldo, C. 1998. Sexual harassment and assault: Chilling the climate for women in academia. Psychology of Women Quarterly. 22(3), 419-41. DOI: https://doi.org/10.1111/j.14716402.1998.tb00166.x

. Fernando, D. and Prasad, A. 2018. Sex-based 
harassment and organizational silencing: How women are led to reluctant acquiescence in academia. Human Relations. Online-first. DOI: https://doi.org/10.1177/0018726718809164. - Dragsdahl, A. 2018. Studerende bag åbent brev til rektorer: Sexchikane er et nationalt problem. Information. [Online]. [Accessed September 25 2018]. Available from: https://www.information.dk/indland/2018/02/studerende-bagaabent-brev-rektorer-sexchikane-nationalt-problem.

. ESTHE. 2016. It stops now. Ending sexual harassment and violence in third level education. A review of data on the prevalence of sexual violence and harassment of women students in higher education in the European Union. [Online]. [Accessed September 25 2018]. Available from: https:// www.nwci.ie/images/uploads/ESHTE_Data_Review_FULL.pdf.

- Fileborn, B. 2012. Sexual violence and gay, lesbian, trans, intersex and queer communities. ACCSA Resource Sheet, March 1-12. [Online]. [Accessed September 25 2018]. Available from: https://pdfs.semanticscholar.org/dbec/0958799 89f6aaffda09038f4b0fffeee0cc4.pdf.

- Fitzgerald, L.F. and Shullman, S.L. 1993. Sexual harassment: A research analysis and agenda for the 1990s. Journal of Vocational Behavior. 42(1), 5-27. DOI: https://doi.org/10.1006/jvbe.1993.1002 . Fitzgerald, L.F., Gelfand, M.J., and Drasgow, F. 1995. Measuring sexual harassment: Theoretical and psychometric advances. Basic and Applied Social Psychology. 17(4), 425-445. DOI: http:// dx.doi.org/10.1207/s15324834basp1704_2 . Fitzgerald, L.F., Shullman, S.L., Bailey, N., Richards, M., Swecker, J., Gold, Y., Ormerod, M. and Weitzman, L. 1988. The incidence and dimensions of sexual harassment in academia and the workplace. Journal of Vocational Behavior. 32(2), 152-75. DOI: https://doi.org/10.1016/00018791(88)90012-7

- FRA - European Agency for Fundamental Rights. 2015. Violence Against Women: An EUWide Survey. Luxembourg: The European Union. - Gruber, J.E. 1992. A typology of personal and environmental sexual harassment: Research and policy implications for the 199O's. Sex Roles. 26(11-12), 447-464. DOI:

http://dx.doi.org/10.1007/BF00289868

- Hlavka, H.R. 2014. Normalizing sexual violence: Young women account for harassment and abuse. Gender and Society. 28(3), 337-358. DOI: https:// doi.org/10.1177\%2F0891243214526468 - Kenig, S. and Ryan, J. 1986. Sex differences in levels of tolerance and attribution of blame for sexual harassment on a university campus. Sex Roles. 15(9-10), 535-49. DOI: https://doi.org/ $10.1007 / \mathrm{BF} 00288230$

- Latcheva, R. 2017. Sexual harassment in the European Union: A pervasive but still hidden form of gender-based violence. Journal of Interpersonal Violence. 32(12), 1821-1852. DOI: 10.1177/ 0886260517698948

- Leskinen, E.A., Cortina, L.M. and Kabat, D.B. 2011. Gender harassment: Broadening our understanding of sex-based harassment at work. Law and Human Behavior. 35(1), 25-39. DOI:

10.1007/s10979-010-9241-5

- Mayekiso, T.V. and Bhana, K. 1997. Sexual harassment: Perceptions and experiences of students at the University of Transkei. South African Journal of Psychology. 27(4), 230-35. DOI: https:// doi.org/10.1177/008124639702700405 - Mazer, D.B. and Percival, E.F. 1989. Students' experiences of sexual harassment at a small university. Sex Roles. 20(1-2), 1-22. DOI: https:// doi.org/10.1007/BF00288023

- Mazzeo, S., Bergman, M.E., Buchanan, N.T., Drasgow, F. and Fitzgerald, L. 2001. Situationspecific assessment of sexual harassment. Journal of Vocational Behavior. 59(1), 120-131. DOI: https://doi.org/10.1006/jvbe.2000.1781

- Mcmaster, L.E., Connolly, J., Pepler, D. and Craig, W.M. 2002. Peer to peer sexual harassment in early adolescence: A developmental perspective. Development and Psychopathology. 14(1), 91-105.

- Mills, S. 2008. Language and Sexism. Cambridge: Cambridge University Press.

- Olson, L.N., Coffelt, T.A., Ray, E.B., Rudd, J., Botta, R., Ray, G., and Kopfman, J.E. 2008. "I'm all for equal rights, but don't call me a feminist": Identity dilemmas in young adults' discursive representations of being a feminist. Women's Studies in Communication. 31(1), 104-132. DOI: https://doi.org/10.1080/07491409.2008.1016 2524

- Phillips, L.M. 2000. Flirting with Danger: Young Women's Reflections on Sexuality and Domination. New York: New York University Press.

- Phipps, A. and Young, I. 2015. 'Lad culture' in higher education: Agency in the sexualization debates. Sexualities. 18(4), 459-479. DOI: http:// dx.doi.org/10.1177/1363460714550909

- Riger, S. 1991. Gender dilemmas in sexual harassment policies and procedures. American Psychologist. 46(5), 497-505. DOI: http:// dx.doi.org/10.1037/0003-066X.46.5.497

- Rotundo, M., Nguyen, D.H. and Sacket, P.R. 2001. A meta-analytic review of gender differences in perceptions of sexual harassment. Journal of 
Applied Psychology. 86(5), 914-922. DOI: http:// dx.doi.org/10.1037/0021-9010.86.5.914

- Till, F. 1980. Sexual harassment: A report on the sexual harassment of students. Washington, DC: National Advisory Council on Women's Educational Programs. [Online]. [Accessed September 25 2018]. Available from:

https://files.eric.ed.gov/fulltext/ED197242.pdf. - Tolman, D., Spencer, R., Rosen-Reynosa, M. and Porche, M. 2003. Sowing the seeds of violence in heterosexual relationships: Early adolescents narrate compulsory heterosexuality. Journal of Social Issues. 59(1), 159-178. DOI:

http://dx.doi.org/10.1111/1540-4560.t01-1 00010

- Vachhani, S. and Pullen, A. 2019. Ethics, politics and feminist organizing: Writing feminist infrapoli- tics and affective solidarity into everyday sexism. Human Relations. 72(1), 23-47. DOI:

$10.1177 / 0018726718780988$

- Welsh, S., Carr, J., MacQuarrie, B. and Huntley, A. 2006. I'm not thinking of it as sexual harassment: Understanding harassment across race and citizenship. Gender \& Society. 20(1), 87-107. DOI: $10.1177 / 0891243205282785$

-Whitley, L. and Page, T. 2015. Sexism at the centre: Locating the problem of sexual harassment. New Formations. 86, 34-53. DOI: 10.3898/NEWF.86.02.2015

. Wilson, F. 2000. The social construction of sexual harassment and assault of university students. Journal of Gender Studies. 9(2), 171-187. DOI: https://doi.org/10.1080/713677982 